\title{
The use of emergency department and outpatient clinics by Syrian refugees
}

\author{
Necmi Baykan, Mehmet Ali \\ Aslaner
}

Nevşehir State Hospital, Emergency Department, Nevşehir, Turkey

\section{Correspondence to:}

Necmi Baykan, M.D.

Ragıp Üner Neighborhood

50130, Nevşehir

Turkey

drnecmibaykan@gmail.com
Background Displacement after a war or an armed conflict always leads to unexpected health problems, both among migrating people and in places to which new people have migrated. This study aimed to determine the health care needs and trends of Syrian patients.

Methods This retrospective study was conducted in a secondary care hospital in the city of Nevssehir, in central Turkey, between January 2013 and December 2017. All Syrian patients who visited the outpatient clinics and emergency department (ED) were enrolled in the study.

Results Over a span of five years, 41723 Syrian patients visited the hospital's outpatient clinics and ED. The patients' median age was 23 (inter-quartile range $(I Q R)=7-34)$, and $57.7 \%$ of them were female. In 2017 , one-third of the Syrian patients visited the ED, a rate that was higher than that found among local patients $(30.3 \%$ vs $25.0 \%, P<0.001$, respectively). The rate of pediatric clinic admissions among Syrian patients was about four times greater than the rate of local patients (20.1\% vs $5.2 \%, P<0.001$, respectively), and Syrians' rate of admission to the obstetrics and gynecology clinic was about three times greater than the rate of local patients' admissions ( $12.3 \%$ vs $4.3 \%$, $P<0.001$, respectively).

Conclusions This study showed that Syrian patients' visits to the hospital, and especially the ED, are increasing. Further, the needs and expectations of these patients in terms of health care are different from local demands. New approaches should be applied to provide an appropriate use of health care facilities.

War is a public health problem that leads to the destruction of nature and humankind; it is a threat to social life, and world leaders have agreed that there is a global refugee and migration crisis today stemming from battles, armed conflicts, and human rights violations in many parts of the world [1]. When it comes to migration, those countries that border states without conflict as well as overseas countries, are becoming an option for people fleeing undesirable locations.

Turkey has been one of the countries with the highest rates of immigration arrivals since the start of the Syrian civil war in 2011. Officially, more than 3.5 million Syrians were recorded by the Disaster and Emergency Management Authority as being in Turkey as of April 2018 [2]. This number accounts for roughly 4.4\% of Turkey's population. In Nevşehir, where the study was conducted, the number of Syrian refugees in 2017 was reported by the Directorate General for Migration Management at 7.819; this accounts for $2.69 \%$ of the province's population [3].

Healthcare is an important challenge for Syrian refugees, due to the language barrier, differences in cultural background, and the physical and psychological distur- 
bances they face after trauma [4]. Further, there is not enough data regarding in which health care areas they need care and which outpatient or emergent care clinics they prefer when they visit the hospital. This study aims to determine which clinics are preferred by Syrian patients and to compare this data to the use of these clinics by other local patients.

\section{METHODS}

\section{Study design}

This retrospective study was conducted in a secondary care hospital in Nevşehir, central Turkey, between January 2013 and December 2017. Few data were available for analysis prior to 2013; therefore, the data were collected beginning with that year. All patients (Syrian and local, separately) who visited an outpatient clinic or the emergency department (ED) were enrolled in the study. Informed consent form was not asked for due to study design. Nevşehir Hacı Bektaş University Ethics Committee approved the study (2018.05.62). The study protocol was previously published on ClinicalTrials.gov (NCT03040843).

The hospital is the city's largest public health care facility, and it has the most admissions in the city. All Syrian refugees' health care payments are paid by the government health insurance system, and health insurance is valid only in the city where a person is registered as living; therefore, nearly all of the patients who are registered in Nevşehir visit this public hospital when they are in need of health care.

\section{Data collection}

Data on Syrian refugees and other patients were obtained from the hospital's medical records. Demographic characteristics, first diagnoses upon admission, type of clinic visited, and the patients' final status were recorded. The International Statistical Classification of Diseases and Related Health Problems $10^{\text {th }}$ Revision (ICD-10) was used to define patients' first diagnoses. In cases of missing data, the patients were excluded from the study.

\section{Data analysis}

Statistical analyses were performed using IBM SPSS Statistics for Windows, Version 21 (IBM, Armonk, NY, USA). Continuous variables were presented as median values and interquartile ranges (IQRs). Categorical variables were summarized as frequencies and percentages. Categorical variables were compared using Pearson $\chi^{2}$ or Fisher exact test. A critical $\alpha$ value of .05 was accepted as statistically significant.

\section{RESULTS}

Between 2013 and 2017, 41723 hospital visits were made by Syrian patients, including outpatient clinics and ED. The patients' median age was 23 (IQR $=7-34$ ), and $57.7 \%$ of them were female. During the study period, $52.2 \%$ of all Syrian hospital visits occurred in $2017,32.6 \%$ in $2016,11.1 \%$ in $2015,3.8 \%$ in 2014 , and $0.3 \%$ in 2013.

Symptoms, signs, and abnormal clinical and laboratory findings (ICD-10, R00-R99) were the most common diagnostic codes, at $18.1 \%$ (which were $66.4 \%$ pain related codes, $8.2 \%$ nausea-vomiting, $3.9 \%$ fever, and others), followed by diseases of the respiratory system (ICD-10, J00-J99) at 17.0\% (which were 43.4\% upper respiratory tract [non-infection] related codes, $42 \%$ upper respiratory tract infection, $11.8 \%$ lower respiratory tract infection, and others). Factors influencing health status (ICD-10, Z00-Z99) accounted for $15.1 \%$ of diagnostic codes (which were 50.9\% general child/adult medical examination, 39\% pregnancy related codes, and others), and diseases of the musculoskeletal system and connective tissue (ICD-10, M00-M99) were 10.5\%.

The patient's discharge was the final decision for $91.3 \%$ of all Syrian patients, an admission decision accounted for $6.9 \%$ of them, and $1.8 \%$ were referred to another hospital. Of all these patients, $31.1 \%$ visited the ED, and $68.9 \%$ visited an outpatient clinic. Of these ED visits, $87.2 \%$ resulted in the patient being discharged, $12.2 \%$ were admitted, and $0.6 \%$ were referred.

In the last five years, the number of Syrian patients in this city has increased exponentially (Table 1). This increase outpaced that of other patients. The rate of Syrian to non-Syrian ED visits was higher than the rate of Syrian to non-Syrian outpatient clinic visits as 54.5\% for all years. While this rate was $133.3 \%$ in 
Table 1. Numbers of Syrian patients who visited the outpatient clinics and emergency department each year (2013-2017)

\begin{tabular}{|c|c|c|c|c|c|c|c|c|c|c|c|}
\hline & & 2013 & $\%$ & 2014 & $\%$ & 2015 & $\%$ & 2016 & $\%$ & 2017 & $\%$ \\
\hline \multirow{2}{*}{ Outpatient clinics } & Syrian patients (n) & 92 & \multirow{2}{*}{0.03} & 1203 & \multirow{2}{*}{0.3} & 2964 & \multirow{2}{*}{0.5} & 9292 & \multirow{2}{*}{1.4} & 15195 & \multirow{2}{*}{2.2} \\
\hline & Other patients (n) & 314713 & & 446548 & & 593386 & & 652903 & & 691782 & \\
\hline \multirow{2}{*}{ Emergency department } & Syrian patients (n) & 33 & \multirow{2}{*}{0.07} & 392 & \multirow{2}{*}{0.5} & 1660 & \multirow{2}{*}{0.9} & 4289 & \multirow{2}{*}{1.9} & 6603 & \multirow{2}{*}{2.9} \\
\hline & Other patients (n) & 47024 & & 80205 & & 184566 & & 220155 & & 230675 & \\
\hline
\end{tabular}

2013, it was only $31.8 \%$ in 2017. The rate of ED to clinic visits amongst refugees was higher than that of non-refugee population (36\% and $15 \%$, respectively) in 2013 . These rates of refugee and non-refugee population were $43 \%$ and $33 \%$ (respectively) in 2017.

During 2017, the year in which the most hospital admissions were seen, one-third of Syrian patients visited the ED; this rate was higher than that of other patients (30.3\% vs $25.0 \%, P<0.001$, respectively) (Table 2). The rate of pediatrics admissions among Syrian patients was about four times greater than among other patients ( $20.1 \%$ vs $5.2 \%, P<0.001$, respectively), and Syrians' rate of obstetrics and gynecology $(O \& G)$ admissions was about three times greater than the rate of other patients' admissions $(12.3 \%$ vs $4.3 \%, P<0.001$, respectively). Diseases of the respiratory system were the most common diagnoses among Syrian patients, accounting for about one-fifth of all diagnoses in 2017 (Table 2).

Table 2. Characteristics of Syrians and other patients who visited to the outpatient clinics and emergency department in 2017

\begin{tabular}{|c|c|c|c|}
\hline & Syaian patientS, N = 21798 & OTHER PATIENTS, $\mathrm{N}=922456$ & P-value \\
\hline \multicolumn{4}{|l|}{ Number of admissions (\%): } \\
\hline Emergency department & $6603(30.3 \%)$ & $15195(25.0 \%)$ & \multirow{10}{*}{$<0.001$} \\
\hline Pediatrics & $4380(20.1 \%)$ & $48070(5.2 \%)$ & \\
\hline Obstetrics and gynecology & $2674(12.3 \%)$ & $39632(4.3 \%)$ & \\
\hline Orthopedics & $1211(5.6 \%)$ & $54860(5.9 \%)$ & \\
\hline ENT & $1077(4.9 \%)$ & $63258(6.9 \%)$ & \\
\hline Internal medicine & $851(3.9 \%)$ & $75053(8.1 \%)$ & \\
\hline Dermatology & $711(3.3 \%)$ & $23030(2.5 \%)$ & \\
\hline Ophthalmology & $700(3.2 \%)$ & $48249(5.2 \%)$ & \\
\hline General surgery & $418(1.9 \%)$ & $32325(3.5 \%)$ & \\
\hline Other & $3173(14.6 \%)$ & $307305(33.3 \%)$ & \\
\hline \multicolumn{4}{|l|}{ Numbers of admission diagnoses (\%) [5]: } \\
\hline Diseases of the respiratory system & $4239(19.4 \%)$ & $139830(15.2 \%)$ & \multirow{10}{*}{$<0.001$} \\
\hline Factors influencing health status & $3407(15.6 \%)$ & $118797(12.9 \%)$ & \\
\hline Symptoms, signs, and abnormal clinical and laboratory findings & $3056(14.0 \%)$ & $116820(12.7 \%)$ & \\
\hline Diseases of the musculoskeletal system and connective tissue & $2366(10.9 \%)$ & $124798(13.5 \%)$ & \\
\hline Diseases of the genitourinary system & $1381(6.3 \%)$ & $54087(5.9 \%)$ & \\
\hline Diseases of the digestive system & $1028(4.7 \%)$ & $40054(4.3 \%)$ & \\
\hline Injury, poisoning, and certain other consequences of external causes & $876(4.0 \%)$ & $29963(3.2 \%)$ & \\
\hline Diseases of the skin and subcutaneous tissue & $838(3.8 \%)$ & $26521(2.9 \%)$ & \\
\hline Diseases of the eye and adnexa & $738(3.4 \%)$ & $49394(5.4 \%)$ & \\
\hline Other & $3869(17.7 \%)$ & $222192(24.1 \%)$ & \\
\hline
\end{tabular}

ENT - ear, nose, and throat

\section{DISCUSSION}

The right to health is considered one of the main issues of human rights, and migration has become one of the most important public health issues for refugees in modern Turkey due to the expected problems of migration such as the language barrier, difficulties in obtaining identity card due to too much applicants at the beginning, living in shelters for a certain period of time, lack of awareness of their rights, and lack of knowledge of the Turkish health care system $[6,7]$. During a five-year period, we found that more than 40000 hospital visits were made by Syrian patients in Nevşehir, Turkey. By and large, these patients were young (median age 23) and female. Although the gender ratio varies across studies, the relatively young median age is similar, as its range is roughly $19-30[4,8]$. 
Since 2013, we found that the number of Syrian patients in Nevşehir has risen dramatically. Whereas there were only 125 Syrian patient visits in 2013, the number grew to 21798 in 2017; more than 50\% of total visits occurred in the last year of the study. A study by Gulacti and colleagues in Turkey reported that ED visits increased by only 6.5\% during five years (2010-2015) by Syrian patients [9]. This rate is very low compared to our results. This discrepancy may be related to where Gulacti et al.'s study was conducted. Their work described an area very close to the Turkey-Syria border, and a number of Syrian refugees have lived there for a long time. By contrast, Nevşehir is located in central Turkey, so Syrian refugees' migration has been increasing in this region over time. While the number of registered Syrian refugees accounted for $0.06 \%$ of this city population in 2014, this rate increased $2.69 \%$ in 2017 [3,10].

When we examined the outcomes of the Syrian patients' visits, we found that the majority of them were discharged from the ED; this rate was similar to that reported in previous studies [9,11]. Another study conducted in Turkey noted that inappropriate ED use by Syrian patients was very high, about 68\% [9]. In addition, roughly one-third of refugee patients use EDs for general health care needs $[4,8]$. In our study, we found that ED use by Syrian patients was higher than that of local patients, and the majority of these patients actually needed only outpatient care. The most likely causes of this situation are the easy access to the ED, less language barrier due to less formal procedures in the ED and limited working hours associated with outpatient clinics $[9,11]$.

In this study, pediatrics visits by Syrian patients were four times greater, and $O \& G$ visits were three times more frequent, than those by local patients. We know that there are nearly 20 million refugees worldwide, and more than half of them are children [12]. All studies regarding refugee patients in Turkey also reported these patients' relatively young ages. Aside from being outnumbered, these children are vulnerable to nutritional deficiencies, infectious diseases, and mental health disorders [6]. Increased deliveries among refugees over the local population is another important situation that can be mostly related to their low socioeconomic status, poverty, forced marriage, reduced use of modern contraceptives, and unwanted pregnancies [13-15]. Each of these factors is a likely cause for the increased need for health care in these areas among refugee patients.

Suggestions:

- Firstly, Syrians living conditions should be improved regarding preventive health care for children, women who are reproductive age and vulnerable groups.

- Syrian refugees need to be educated and referred to the primary health care services for simple complaints in order to reduce the rates of admissions to hospitals.

- Comprehensive reproductive health services should be integrated into primary health care in order to prevent unplanned or forced pregnancies.

- Language resources need to be put in, especially, primary health care services and other services until language learning process is completing.

- Home Health Care Services are used in many cities in Turkey. This care can also be extended for refugees.

- Finally, national and local health goverments need to increase support for EDs, pediatrics, and O\&G clinics due to increased demand from refugees.

\section{CONCLUSIONS}

As a result of rapidly increasing number of refugees, the demands, needs, and expectations for health care in Turkey are changing. The present study draws attention to these patients' tendency to visit the ED and other, specific clinics, such as pediatrics and obstetrics and gynecology, compared to the native Turkish population, although the majority of these patients actually needed only outpatient care. Providing quality health care in primary health care settings, extending preventive health care, and taking precautions regarding language problems would make care more accessible and easier to provide, while also reducing unnecessary visits by these patients to the hospital. 
Ethics and consent: Nevşehir Hacı Bektaş University Ethics Committee approved the study.

Funding: None.

Authorship contributions: NB and MAA contributed to the conception, design and drafting of the work; NB revised it critically for important intellectual content and approved the version to be published.

Competing interests: The authors have completed the Unified Competing Interest form at www.icmje.org/ coi_disclosure.pdf (available on request from the corresponding author) and declare no competing interests.

1 The Communique of the Symposium. War, Migration and Health. Toplum ve Hekim. 2016;31:150-5.

2 Directorate General of Civil Aviation. Accessed 31.05.2018, at http://web.shgm.gov.tr/en.

3 Çakir O, Evren S, Tören E, Kozak N. Utilizing the sustainable livelihoods approach to evaluate tourism development from the rural host communities' point of view: the case of Cappadocia (Turkey). Geo J Tour Geosites. 2018;21:7-25.

4 Tahirbegolli B, Çavdar S, Sümer EÇ, Akdeniz SI, Vehid S. Outpatient admissions and hospital costs of Syrian refugees in a Turkish university hospital. Saudi Med J. 2016;37:809-12. Medline:27381545 doi:10.15537/smj.2016.7.13839

5 International Statistical Classification of Disease and Related Health Problems. Tenth Revision. Geneva: World Health Organization; 2004.

6 Güngör A, Çatak Aİ, Çuhaci Çakir B, Oden Akman A, Karagol C, Koksal T, et al. Evaluation of Syrian refugees who received inpatient treatment in a tertiary pediatric hospital in Turkey between January 2016 and August 2017. Int Health. 2018;10:371-5. Medline:29850818 doi:10.1093/inthealth/ihy034

7 Torun P, Mücaz Karaaslan M, Sandıklı B, Acar C, Shurtleff E, Dhrolia S, et al. Health and health care access for Syrian refugees living in İstanbul. Int J Public Health. 2018;63:601-8. Medline:29629476 doi:10.1007/s00038-018-1096-4

8 Karakus A, Yengil E, Akkucuk S, Cevik C, Zeren C, Uruc V. The reflection of the Syrian civil war on the emergency department and assessment of hospital costs. Ulus Travma Acil Cerrahi Derg. 2013;19:429-33. Medline:24214784 doi:10.5505/tjtes.2013.78910

9 Gulacti U, Lok U, Polat H. Emergency department visits of Syrian refugees and the cost of their healthcare. Pathog Glob Health. 2017;111:219-24. Medline:28720037 doi:10.1080/20477724.2017.1349061

10 Erdoğan MM. Syrians in Turkey: Social Acceptance and Integration. The Hacettepe University Migration and Politics Research Centre; 2017.

11 Duzkoylu Y, Basceken SI, Kesilmez EC. Physical trauma among refugees: Comparison between refugees and local population who were admitted to emergency department-experience of a state hospital in Syrian Border District. J Environ Public Health. 2017;2017: 8626275. Medline:28694829 doi:10.1155/2017/8626275

12 Williams B, Cassar C, Siggers G, Taylor S. Medical and social issues of child refugees in Europe. Arch Dis Child. 2016;101:839-42. Medline:27470163 doi:10.1136/archdischild-2016-310657

13 Büyüktiryaki M, Canpolat FE, Alyamaç Dizdar E, Okur N, Kadıŏlu Şimşek G. Neonatal outcomes of Syrian refugees delivered in a tertiary hospital in Ankara, Turkey. Confl Health. 2015;9:38. Medline:26697104 doi:10.1186/s13031015-0066-1

14 Özgülnar N. Problems of Women-War, Migration and Health; Experience of Turkey. Ankara: Turkish Medical Association Publications; 2016.

15 Samari G. Syrian Refugee Women's Health in Lebanon, Turkey, and Jordan and Recommendations for Improved Practice. World Med Health Policy. 2017;9:255-74. Medline:29051840 doi:10.1002/wmh3.231 